\title{
HLA antigens in multiple sclerosis amongst Indians
}

\author{
NH WADIA, VS TRIKANNAD, PR KRISHNASWAMY \\ From the Jaslok Hospital and Research Centre, Bombay, India
}

SUMMARY The infrequency of multiple sclerosis in India may have genetic implications. We found (a) the HLA-A3 and HLA-B7 haplotypes amongst Indians to be lower than those reported in Caucasians, (b) no excess of HLA-A3 and HLA-B7 amongst our 27 multiple sclerosis patients compared to 330 controls; instead it was the reverse, (c) HLA-B12 as high as $74 \%$ in the "clinically definite" cases, against only $9 \%$ in controls, (d) a significant relative risk of MS amongst Indians with HLA-B12 haplotype. Attention is drawn to the higher incidence of MS amongst the small Parsee community and the high association of HLA-B12 in these patients.

The association between histocompatibility antigens and greater susceptibility to multiple sclerosis (MS) has been generally accepted. There is now good evidence that amongst Caucasians, the histocompatibility antigens HLA-A3 and HLA-B7, and more significantly the mixed culture lymphocyte determinant HLA-Dw2, occur substantially more often in patients with MS than in the population at large of the same area. ${ }^{1-6}$ It is noteworthy that population studies in Israel, Japan and Jordan have shown no excess of HLA-A3 and HLA-B7, 6 ? although an association with a locally defined Ialike antigen closely related to DRw4 and DRw7 has been found in Jordan. ${ }^{6} 8$

We were interested in determining whether there would be any such association of HLA-antigens with MS patients in India, considering amongst other variable factors that the disease has a lower incidence in this country. ${ }^{9}$

\section{Patients, materials and methods}

Twenty-seven patients seen by one of us (NHW) over the last 15 years could be recalled for the study. The diagnosis of MS was made clinically and the cases subclassified using the criteria of McDonald and Halliday. ${ }^{10}$ Visual evoked response and estimation of CSF immunoglobulins carried out in several of our cases, were not used to make the diagnosis. Nineteen patients were considered as "clinically definite" cases. They had multiple lesions in the nervous system and a remitting

Address for reprint requests: $\mathrm{Dr} \mathrm{NH}$ Wadia, 15, Dr G Deshmukh Marg, Bombay 400 026, India.

Accepted 5 May 1981 relapsing course of the disease with more than two episodes. The disease had been present for at least a year, and often for several years, the age at onset being 20 to 40 years. Among the rest, two were considered as "early probable or latent", two were "progressive probable", one was "progressive possible" and three were suspected cases. These patients were detected randomly from the usual ethnic mix seen by neurologists in clinical practice in Bombay. Normal controls (330) were also randomly drawn mostly from families in Bombay, who underwent tissue typing as a screening procedure for related donors in the kidney transplant programme at this hospital. These controls came from 100 families representative of the heterogenity of the Indian population. Fifty-seven sera representing different HLA antigens of the A, B and $\mathrm{C}$ series kindly donated by Professors JJ Van Rood and F Kissmeyer-Nielsen were used for tissue typing, employing the lymphocyte microtoxicity technique. ${ }^{11}$

\section{Results}

A striking finding among the patient population was that HLA-B12 occurred at a frequency in excess of what was found in the control population (table 1).

Table 1 Association of $H L A-B 12$ with cases of multiple sclerosis

\begin{tabular}{|c|c|c|c|c|}
\hline \multirow[t]{2}{*}{ Classification } & \multicolumn{2}{|c|}{ Patients } & \multicolumn{2}{|c|}{ Controls } \\
\hline & No. & $\begin{array}{l}\text { HLA-BI2 } \\
\text { Positive No. (\%) }\end{array}$ & No. & $\begin{array}{l}\text { HLA-BI2 } \\
\text { Positive No. (\%) }\end{array}$ \\
\hline $\begin{array}{l}\text { Clinically definite } \\
\text { Others }\end{array}$ & $\begin{array}{r}19 \\
8\end{array}$ & $\begin{array}{c}14(74)^{*} \\
3(36)\end{array}$ & - & - \\
\hline Total & 27 & $17(63)^{*}$ & 330 & $28(9)$ \\
\hline
\end{tabular}

${ }^{*} p<0.001$. 
The significance of this finding was further confirmed by calculating the relative risk of MS by the formula:

Number of patients positive for antigen

$\times \quad$ Number of controls negative for antigen

Number of patients negative for antigen

$\times \quad$ Number of controls positive for antigen

The relative risk was as high as $\mathbf{3 0}$ in the "clinically definite" cases and 18 in the overall series (table 2).

Table 2 Relative risk and HLA antigen association in multiple sclerosis

\begin{tabular}{llll}
\hline Series & HLA antigens & $\begin{array}{l}\text { Antigen frequency } \\
\text { patients/controls }\end{array}$ & $\begin{array}{l}\text { Relative } \\
\text { risk }\end{array}$ \\
\hline Westerns & A3 & $36 / 27$ & 2 \\
& B7 & $35 / 27$ & 2 \\
$\begin{array}{l}\text { Indian } \\
\begin{array}{l}\text { All cases } \\
\text { Clinically definite } \\
\text { cases }\end{array}\end{array}$ & B12 & $67 / 18$ & 7 \\
\hline
\end{tabular}

We did not detect any excess of the A3 and B7 antigens among our patients. In fact a negative correlation was noted though both the antigens occurred less frequently in our patients and controls than reported amongst Caucasians. ${ }^{12}$ Only a single patient was found to possess A3 antigen and none was positive for B7. Figures for the control population were $30(9 \%)$ and $32(10 \%)$ respectively (A3 and B7 amongst Caucasians is about $27 \%$ ). ${ }^{12}$

\section{Discussion}

The low incidence of MS in the tropics (including India) has been explained on the basis of difference in environmental factors such as climate, hygiene, etc. With new information on HLA association with MS, a genetic predilection to this disease with superimposition of environmental factors is likely. However, available data on HLA association is still incomplete and at times contradictory. ${ }^{13}$

The most significant of our observations has been the demonstration of a clearly and statistically acceptable excess of HLA-B12 in patients being as high as $74 \%$ in the "clinically definite" cases as against only $9 \%$ in controls. The demonstrated higher relative risk for Indians with HLA-B12 for MS is especially striking especially when compared with the relative risk of two for HLA-A3 and B7, or of seven for Dw2 among Caucasians. This is further stressed by comparing the known relative risk of 11 for Addison's disease in those with Dw3, or three for Grave's disease in Caucasians with HLA-B8, and the almost diagnostic relative risk of 88 for ankylosing spondylitis in those with HLA-
B27.

This, along with our earlier communication, ${ }^{14}$ represents the first study of HLA association with MS in any Indian population group. It should be noted that in Japan and Israel no HLA association for MS has been detected. In Jordan, a higher relative risk was found amongst those with a locally defined Ia-like antigen closely related to DRw4 and DRw7, but not with HLA-A3 or B7. It is noteworthy that DRw7 is in linkage disequilibrium with HLAB12,15 making our observations comparable and more interesting.

Poser ${ }^{13}$ has drawn special attention to the importance of a decreased incidence of certain histocompatibility antigens in MS, which suggests the possible existence of protective genetic factors. This negative correlation appears to exist for HLA-B12 in patients with MS reported from USA, Canada, Denmark, Norway, and Germany in contrast to the positive correlation in our patients.

In the present study, eight of the 27 patients of the whole series and six of the 19 "clinically definite" cases were Parsees. It is striking that nearly one third of the patients came from this small community $(70,000$ in a population of 7 million in Bombay). This confirms the earlier observation ${ }^{9}$ that Parsees were apparently more susceptible to MS. It is of interest that six of the eight Parsee patients from the whole series and five of the six who were clinically considered as definitely suffering from MS possessed HLA-B12. Statistical evaluation of this data has not been made because sufficient control data of the Parsees alone has yet to be gathered, there being only eight Parsees in our 330 controls. The relatively larger number of Parsees amongst patients does not detract from the overall observation of the significance of the HLA-B12 association, because the relative risk remains high ( 15 for the "clinically definite" cases and 25 for the overall series), even when the Parsees are excluded from the series for the purpose of calculation.

Pooled information from different centres all over India and study of pure ethnic groups may help derive more conclusive data. Such studies, including a survey of the Parsee population for the profile of HLA-antigens is under progress.

We thank Miss Parvin Batlivala for her technical assistance, Professors JJ Van Rood and F KissmeyerNielsen for donation of sera and Dr TH Rindani, the Medical Director of the Jaslok Hospital and Research Centre for support and encouragement.

\section{References}

${ }^{1}$ Naito S, Namerow N, Mickey MR, Terasaki PI. 
Multiple Sclerosis association with HLA 3. Tissue Antigens 1972;2:1-4.

${ }^{2}$ Bertrams J, Kuwert E, Liedtke U. HLA antigens and multiple sclerosis Tissue Antigens 1972;2:405-8.

${ }^{3}$ Jersild C, Fog T, Hansen GS, Thomsen M, Svejgaard A, Dupont B. Histocompatibility determinants in multiple sclerosis with special reference to clinical course. Lancet $1973 ; 2: 1221-5$.

${ }^{4}$ Dausset J, Hors J. Some contributions of the HLA complex to the genetics of human diseases. Transplant Rev 1975;22:44-74.

${ }^{5}$ Whitaker JN, Hermann KL, Rogentine GN, Stein SF, Kollins LL. Immunogenetic analysis and serum viral antibody titres in multiple sclerosis. Arch Neurol 1976;33:399-403.

${ }^{6}$ Batchelor JR, Compston A, McDonald WI. The significance of the association between HLA and Multiple Sclerosis. Br Med Bull 1978;34:279-84.

' Brautbar C, Alter MM, Kahana E. HLA antigen in Multiple sclerosis. Neurology (Minneap) 1976; 26:2:50-3.
${ }^{8}$ Kurdi A, Ayesh I, Abdallat A, et al. Different B Lymphocyte Alloantigens associated with Multiple Sclerosis in Arabs and North Europeans. Lancet 1977; 1:1123-5.

${ }^{9}$ Singhal BS, Wadia NH. Profile of Multiple Sclerosis in the Bombay Region. On the basis of critical clinical appraisal. J Neurol Sci 1975;26:259-70.

${ }^{10}$ McDonald WI, Halliday AM. Diagnosis and classification of Multiple Sclerosis. Br Med Bull 1977;33: 4-8.

${ }^{11}$ Manual of Tissue Typing Techniques. National Institute of Allergy and Infectious diseases, 1974;20.

${ }^{12}$ Acheson ED. Epidemiology of Multiple Sclerosis. Br Med Bull 1977;33:9-14.

${ }^{13}$ Poser CM. Multiple Sclerosis-A critical update. Med Clin N Amer 1979;63:729-43.

14 Wadia NH, Trikannad VS, Krishnaswamy PR. Association of HLA-B12 with Multiple Sclerosis in India. Tissue Antigens 1980;15:90-3.

${ }^{15}$ Bodmer WF, Bodmer JG. The evolution of the HLA system. Br Med Bull 1978;34:301-16. 